LETTER TO JMG

\title{
Mitochondrial DNA haplogroups influence the Friedreich's ataxia phenotype
}

\author{
M Giacchetti, A Monticelli, I De Biase, L Pianese, M Turano, A Filla, G De Michele, S Cocozza
}

J Med Genet 2004;41:293-295. doi: 10.1136/jmg.2003.015289

$\mathrm{F}$ iedreich's ataxia, an autosomal recessive neurodegenerative disorder, is the most common hereditary ataxia among white people. ${ }^{1}$ The disease is characterised by gait and limb ataxia, dysarthria, absent tendon reflexes, Babinski's sign, impairment of position and vibratory senses, scoliosis, and pes cavus. ${ }^{2}$ Cardiac manifestations are prominent in some cases. $^{3}$ Diabetes mellitus or carbohydrate intolerance is frequently described. ${ }^{1}$ The age of onset is variable. The disease usually comes at puberty but several cases have become symptomatic after 40 years. ${ }^{4}$ The molecular defect that occurs in Friedreich's ataxia is the trinucleotide GAA expansion in the first intron of the X25 gene. This gene encodes for a 210 aa mitochondrial protein called frataxin. ${ }^{5}$ Levels of frataxin mRNA and protein are severely reduced as a result of this expansion. ${ }^{5}$ Although the exact physiological function of frataxin is not known, its involvement in iron-sulphur (Fe-S) cluster biogenesis ${ }^{6}$ has been suggested.

The Friedreich's ataxia phenotype shows a variable expression with respect to the age of onset and the presence of some signs or symptoms. Disease duration has been proposed to influence dysarthria, decreased vibration sense, optic atrophy, and diabetes. ${ }^{7}$ Some Friedreich's ataxia phenotype features are strongly correlated with GAA expansion size. An inverse relationship has been demonstrated between GAA repeat size and the age of onset. ${ }^{78}$ Friedreich's ataxia with retained reflexes or absence of cardiomyopathy was associated with shorter expansions. In a previous report, we demonstrated that GAA size accounts for about $70 \%$ of the onset age variance, ${ }^{8}$ with sibling age of onset independently accounting for an additional 13\%.' Then we suggested that siblings shared genetic or environmental factors that, in addition to the GAA size, influence the age of onset. Modifier genes are defined on the basis of their ability to modulate the clinical phenotype of individuals with monogenic and multigenic diseases. Mitochondrial DNA (mtDNA) could be considered a candidate modifier factor for neurodegenerative disorders, since mitochondrial oxidative stress is thought to be involved in the pathogenesis of these diseases. ${ }^{10}$ MtDNA is maternally inherited and highly polymorphic. Population specific mtDNA polymorphisms create groups of related mtDNA haplotypes, or haplogroups. ${ }^{11}$ The majority of the European mtDNAs can be classified within nine mtDNA haplogroups, designated as $\mathrm{H}, \mathrm{I}, \mathrm{J}, \mathrm{K}, \mathrm{T}, \mathrm{U}, \mathrm{V}, \mathrm{W}$, and $\mathrm{X} .^{11}$ Several haplogroups have been associated with polymorphic biological features in healthy individuals. In particular, haplogroup $\mathrm{J}$ has been associated with increased longevity in Europeans and reduced efficiency of ATP production during oxidative phosphorylation. ${ }^{12}$ Moreover, the $\mathrm{T}$ haplogroup has been associated with reduced spermatozoa motility. ${ }^{13}$ MtDNA haplogroups can also play an important role in modulating disease expression. Extensive analysis of the mtDNAs of patients with Leber hereditary optic neuropathy has revealed that certain mtDNA haplogroups are prone to expression of the disease more than others. ${ }^{14}$

\section{Key points}

- Friedreich's ataxia, the most common hereditary ataxia among white people, is caused by a trinucleotide GAA expansion in the X25 gene.

- Friedreich's ataxia is characterised by a variable phenotype which may also include hypertrophic cardiomyopathy and diabetes.

- We report an influence of the mitochondrial DNA (mtDNA) haplogroups on the Friedreich's ataxia phenotype.

- Patients belonging to the U mtDNA haplogroup class were found to have a delay of 5 years in the disease onset and a lower rate of cardiomyopathy.

Individuals classified as haplogroups $\mathrm{J}$ or $\mathrm{K}$ demonstrate a significant decrease in risk of Parkinson's disease, as against individuals carrying the most common haplogroup $\mathrm{H}^{15}$ In addition, tRNA ${ }^{\text {gln }}$ nucleotide position 4336 variant in individuals belonging to the haplogroup $\mathrm{H}$ is associated with late onset Alzheimer's disease. ${ }^{16}$

\section{SUBJECTS AND METHODS}

\section{Sample and DNA extraction}

A total of 99 patients with Friedreich's ataxia ( 54 men and 45 women), with known GAA expansion sizes, and 48 control individuals, all from southern Italy, were included in the present study. All of them were informed on the aims of the study and gave their informed consents to the genetic analysis. Genomic DNA was isolated from blood nucleated cells (2 ml of peripheral blood) according to standard techniques. Because of the maternal inheritance of mtDNA, only unrelated patients were selected for the study.

\section{Polymerase chain reactions and electrophoresis}

The GAA triplet repeat sizes were typed by polymerase chain reaction (PCR). Primers for the PCR were designed and numbered according to GenBank sequence accession numbers U43748. PCR was performed as previously described. ${ }^{17}$ The smaller and the larger in each pair of GAA alleles were indicated as GAAl and GAA2, respectively.

\section{MtDNA haplogroup analysis}

Haplogroup typing has been carried out by restriction analyses of mtDNA according to De Benedictis et al. ${ }^{12}$ For each individual, mtDNA was amplified with the appropriate

Abbreviations: ANCOVA, analysis of covariance; PCR, polymerase chain reaction 
oligoprimers to analyse the following restriction sites: AluI 7025, DdeI 10394, DdeI 1715, NlaIII 4577, AvaII 8249, HaeII 9025, HinfI 12308 (restriction site created by mismatched primers), HinfI16065, BamHI 13366, BamHI 16389. PCR fragments were digested with the appropriate enzymes and then separated on a 3\% agarose Metaphore gel. Subjects were classified in a certain mtDNA haplogroup according to the presence or absence of these polymorphic sites.

\section{Statistical analysis}

All statistical analyses were performed using statistical software program SISA Binomial and Statistical for Windows version 4.5 , StatSoft Inc.

\section{Results and discussion}

The GAA expansion size is strongly related to the age of onset, accounting for about $70 \%$ of variance. ${ }^{9}$ To explore the influence of other genetic factors, which modify the age of onset in addition to the GAA size, we investigated the possible role of mtDNA haplogroups on the Friedreich's ataxia clinical manifestations. We classified our subjects into the nine European mtDNA haplogroups: H, I, J, K, T, U, V, W, and $\mathrm{X}$. We were able to include 128 individuals (87.1\%)-84 patients and 44 controls-in defined haplogroups. The mean age of onset of Friedreich's ataxia in our patients was 15.8 (standard deviation, 8.52) years, mean GAAl length was 654 (238) repeats and mean GAA2 length was 869 (191) repeats. No significant difference was found in the frequency distribution of mtDNA haplogroups between patients with Friedreich's ataxia and healthy controls $\left(\chi^{2}=8.35, \mathrm{p}>0.05\right)$, see table 1 .

To test the hypothesis that mtDNA haplogroups could influence the age of onset, we performed a multiple regression analysis. The haplogroup independent variable was coded as $0=$ absence and $\mathrm{l}=$ presence. A stepwise multiple regression of age at onset on GAAl size, GAA2 size and mtDNA haplogroups showed that only GAAl size and haplogroup U contributed significantly to the regression (see table 2). In particular we observed that haplogroup U seems to have a protective effect, delaying the age of onset for an average of approximately 5 years. Haplogroups $\mathrm{H}, \mathrm{J}, \mathrm{K}$, and T did not influence the regression significantly. In addition, to control the effect of GAAl, an analysis of covariance (ANCOVA) was performed (independent variable: presence of U; dependent variable: age at onset; covariate: GAAl). ANCOVA confirmed the effect of $U$ haplogroup on onset age ( $F=12.79 ; p<0.001)$, see figure 1 .

As previously stated, variations in disease presentation concern not only the age of onset, but also the presence of several clinical features, such as diabetes and cardiomyopathy. Diabetes mellitus is present in about $14 \%$ of Friedreich's ataxia patients ${ }^{18}$ and it develops, usually, in a late stage of the disease, after a mean disease duration of 15 years. ${ }^{1}$

\begin{tabular}{|c|c|c|}
\hline Haplogroups & $\begin{array}{l}\text { Patients with } \\
\text { Friedreich's ataxia }\end{array}$ & Controls \\
\hline $\mathrm{H}$ & 40 & 15 \\
\hline J & 10 & 1 \\
\hline $\mathrm{K}$ & 7 & 5 \\
\hline $\mathrm{T}$ & 8 & 3 \\
\hline U & 12 & 13 \\
\hline Others* & 22 & 11 \\
\hline
\end{tabular}

Table 2 Multiple regression of age at onset on GAA1 size and mtDNA haplogroups

\begin{tabular}{llll}
\hline & Regression coefficient & Standard error & $\mathbf{p}<$ \\
\hline GAA1 & -0.027 & 0.002 & 0.001 \\
Haplogroup U & 5.545 & 1.550 & 0.001 \\
\hline
\end{tabular}

Age of onset is expressed in years, GAAl size in the number of triplets; haplogroups as absent (0) or present (1). Figures are estimated

regression coefficients and standard errors.

Cardiac involvement in Friedreich's ataxia is well studied and it is characterised by an increased thickness of the ventricular wall, a normal or small left ventricular cavity, and, usually, a normal systolic function. ${ }^{3}$ Occurrence of cardiomyopathy appears to be constant at pathological examination, very frequent at electrocardiography, and less common when echocardiography is used..$^{18}$

We investigated the possible influence of haplogroups on the development of diabetes mellitus and cardiomyopathy in our population sample.

We found no significant relationship between haplogroups and diabetes (data not shown). This finding is not unexpected since diabetes has been demonstrated to be associated more with disease duration than with genetic factors. ${ }^{7}$ On the other hand, the presence of cardiomyopathy has been demonstrated to be influenced by GAAl repeat size. $^{378}$ To take this influence into account, we divided our patients into two subgroups according to their GAAl repeat size. The first group (A) included patients with shorter GAA repeats (less than the mean value of GAAl size of the population), while the second group (B) included patients with larger expansions (more than the mean value of GAAl size of the population). The mean value of GAAl in our population, 654 triplets, is also consistent with the threshold above which frataxin expression is too low to influence the clinical presentation. ${ }^{7}$ Table 3 shows the frequencies of haplogroups $\mathrm{H}, \mathrm{J}, \mathrm{K}, \mathrm{T}$, and $\mathrm{U}$ in patients with Friedreich's ataxia, classified according to the presence or absence of hypertrophic cardiomyopathy, as shown by echocardiographic examination, and to the repeat length. Less frequent haplogroups $\mathrm{V}, \mathrm{X}, \mathrm{W}$, and I were excluded from the analysis.

While in the majority of patients with $\mathrm{H}$ and $\mathrm{J}$ haplogroups, the presence of hypertrophic cardiomyopathy is strongly influenced by repeat size, in patients belonging to

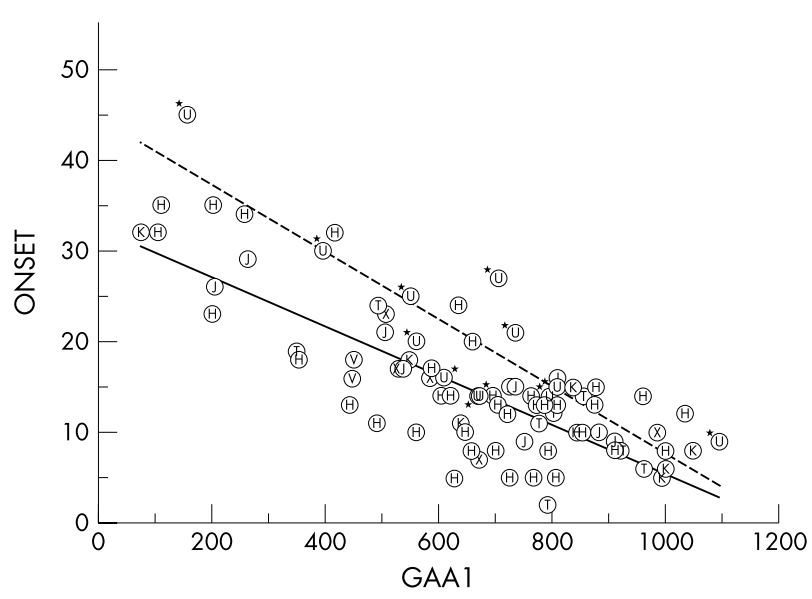

Figure 1 Regression lines (ANCOVA) of GAA1 repeat length and age at onset in 84 patients with Friedreich's ataxia (solid line $=\mathrm{U}$ absent; dashed line $=U$ present). Letters in circles correspond to the haplogroup. 12 patients carrying the $U$ haplogroup are indicated with stars. 
Table 3 Frequencies of haplogroups $\mathrm{H}, \mathrm{J}, \mathrm{K}, \mathrm{T}$, and $\mathrm{U}$ in patients with Friedreich's ataxia, classified according the presence or absence of hypertrophic cardiomyopathy (HCM) and the repeat length

\begin{tabular}{llllll}
\hline & \multicolumn{2}{l}{ Group A } & & \multicolumn{2}{l}{ Group B } \\
\cline { 2 - 3 } \cline { 5 - 6 } Haplogroups & HCM+ & HCM- & & HCM+ & HCM- \\
\hline H & 16 & 4 & 2 & 12 \\
$\mathbf{J}$ & 5 & 1 & 0 & 3 \\
K & 2 & 2 & 3 & 0 \\
T & 2 & 4 & 0 & 2 \\
U & 2 & 5 & 1 & 4 \\
\hline
\end{tabular}

Group A includes patients carrying a GAA expansion $<654$ triplets. Group B includes patients carrying a GAA expansion $\geqslant 654$ triplets. $\mathrm{HCM}+$ / - means the presence or absence of hypertrophic cardiomyopathy.

the $\mathrm{U}$ and $\mathrm{T}$ haplogroups, hypertrophic cardiomyopathy is generally less frequent and independent on the GAA size. Analysing our samples using a Fisher 2 by 5 test, $^{19}$ a significant difference in cardiomyopathy frequency $(p<0.05)$ has been found for patient group A.

In summary, haplogroup $U$ seems also to have a protective effect on the development of the cardiomyopathy in Friedreich's ataxia. Haplogroup U has already been correlated to certain human diseases. Previous reports showed its involvement in the migrainous stroke in the Finnish population. ${ }^{20}$ A protective role of haplogroup $U$ has been suggested in Alzheimer's disease. In Alzheimer's disease, apolipoprotein E $\varepsilon 4$ allele polymorphism has been demonstrated to represent a susceptibility factor. Carrieri et al found that haplogroups $\mathrm{U}$ and $\mathrm{K}$ seem to neutralise the harmful effect of the APOE $\varepsilon 4$ allele. ${ }^{21}$

In this study, we report an influence of haplogroup $U$ on the Friedreich's ataxia phenotype.

Patients belonging to this mtDNA class seem to have a delay in the disease onset and a lower rate of cardiomyopathy. Other populations with different backgrounds should be examined to confirm this data.

\section{ACKNOWLEDGEMENTS}

We wish to thank Dr Giovanni Coppola for the statistical analysis support.

\section{Authors' affiliations}

M Giacchetti, A Monticelli, I De Biase, L Pianese, M Turano, S Cocozza, Dipartimento di Biologia e Patologia Cellulare e Molecolare "L Califano" Università "Federico II", Via S Pansini, 5, 80131 Napoli, Italy A Monticelli, IEOS CNR

L Pianese, M Turano, BioGeM Consortium

A Filla, G De Michele, Dipartimento di Scienze Neurologiche, Università Federico II, Via S Pansini, 5, 80131 Napoli, Italy

Correspondence to: Prof S Cocozza, Dipartimento di Biologia e Patologia Cellulare e Molecolare "L. Califano" Università "Federico II", Via S Pansini, 5, 80131 Napoli, Italy; cocozza@unina.it

Received 10 October 2003

Accepted for publication 22 December 2003

\section{REFERENCES}

1 Harding AE. Friedreich's ataxia: a clinical and genetic study of 90 families with an analysis of early diagnostic criteria and intrafamilial clustering of clinical features. Brain 1981;104:589-620.

2 Filla A, De Michele G, Coppola G, Federico A, Vita G, Toscano A, Uncini A, Pisanelli P, Barone P, Scarano V, Perretti A, Santoro L, Monticelli A, Cavalcanti F, Caruso G, Cocozza S. Accuracy of clinical diagnostic criteria for Friedreich's ataxia. Mov Disord 2000;15:1255-8.

3 Isnard $R$, Kalotka $H$, Durr A, Cossee $M$, Schmitt M, Pousset $F$, Thomas $D$, Brice $A$, Koenig $M$, Komajda M. Correlation between left ventricular hypertrophy and GAA trinucleotide repeat length in Friedreich's ataxia. Circulation 1997:95:2247-9.

4 De Michele G, Filla A, Cavalcanti F, Di Maio L, Pianese L, Castaldo I, Calabrese O, Monticelli A, Varrone S, Campanella G, et al. Late onset Friedreich's disease: clinical features and mapping of mutation to the FRDA locus. J Neurol Neurosurg Psychiatry 1994;57:977-9.

5 Campuzano V, Montermini L, Molto MD, Pianese L, Cossee M, Cavalcanti F, Monros E, Rodius F, Duclos F, Monticelli A, et al. Friedreich's ataxia: autosomal recessive disease caused by an intronic GAA triplet repeat expansion. Science 1996;271:1423-7.

6 Yoon T, Cowan JA. Iron-sulfur cluster biosynthesis. Characterization of frataxin as an iron donor for assembly of [2Fe-2S] clusters in ISU-type proteins. J Am Chem Soc 2003;125:6078-84.

7 Durr A, Cossee M, Agid Y, Campuzano V, Mignard C, Penet C, Mandel JL, Brice A, Koenig M. Clinical and genetic abnormalities in patients with Friedreich's ataxia. N Engl J Med 1996;335:1169-75.

8 Filla A, De Michele G, Cavalcanti F, Pianese L, Monticelli A, Campanella G Cocozza $S$. The relationship between trinucleotide (GAA) repeat length and clinical features in Friedreich ataxia. Am J Hum Genet 1996;59:554-60.

9 De Michele G, Filla A, Criscuolo C, Scarano V, Cavalcanti F, Pianese L, Monticelli A, Cocozza S. Determinants of onset age in Friedreich's ataxia. J Neurol 1998;245:166-8.

10 Orth M, Schapira AH. Mitochondria and degenerative disorders. Am J Med Genet 2001;106:27-36.

11 Torroni A, Huoponen K, Francalacci P, Petrozzi M, Morelli L, Scozzari R, Obinu D, Savontaus ML, Wallace DC. Classification of European mtDNAs from an analysis of three European populations. Genetics 1996; 144:1835-50

12 De Benedictis G, Rose G, Carrieri G, De Luca M, Falcone E, Passarino G, Bonafe M, Monti D, Baggio G, Bertolini S, Mari D, Mattace R, Franceschi C. Mitochondrial DNA inherited variants are associated with successful aging and longevity in humans. FASEB $J$ 1999;13:1532-6.

13 Ruiz-Pesini E, Lapena AC, Diez-Sanchez C, Perez-Martos A, Montoya J, Alvarez E, Diaz M, Urries A, Montoro L, Lopez-Perez MJ, Enriquez JA. Human mtDNA haplogroups associated with high or reduced spermatozoa motility. Am J Hum Genet 2000;67:682-96.

14 Howell N, Oostra RJ, Bolhuis PA, Spruijt L, Clarke LA, Mackey DA, Preston G, Herrnstadt C. Sequence analysis of the mitochondrial genomes from Dutch pedigrees with Leber hereditary optic neuropathy. Am J Hum Genet 2003:72:1460-9.

15 Van der Walt JM, Nicodemus KK, Martin ER, Scott WK, Nance MA, Watts RL, Hubble JP, Haines JL, Koller WC, Lyons K, Pahwa R, Stern MB, Colcher A, Hiner BC, Jankovic J, Ondo WG, Allen FH Jr, Goetz CG, Small GW, Mastaglia F, Stajich JM, McLaurin AC, Middleton LT, Scott BL, Schmechel DE, Pericak-Vance MA, Vance JM. Mitochondrial polymorphisms significantly reduce the risk of Parkinson disease. Am J Hum Genet 2003;72:804-11.

16 Shoffner JM, Brown MD, Torroni A, Lott MT, Cabell MF, Mirra SS, Beal MF, Yang CC, Gearing M, Salvo R, et al. Mitochondrial DNA variants observed in Alzheimer disease and Parkinson disease patients. Genomics 1993;17:171-84.

17 Filla A, De Michele G, Marconi R, Bucci L, Carillo C, Castellano AE, lorio L, Kniahynicki C, Rossi F, Campanella G. Prevalence of hereditary ataxias and spastic paraplegias in Molise, a region of Italy. J Neurol 1992;239:351-3.

18 Filla A, DeMichele G, Caruso G, Marconi R, Campanella G. Genetic data and natural history of Friedreich's disease: a study of 80 Italian patients. J Neurol 1990:237:345-51.

19 Uitenbroek DG. SISA binomial. http://home.clara.net/sisa/binomial.htm 1997 (Accessed 1 January, 2002).

20 Finnila S, Majamaa K. Phylogenetic analysis of mtDNA haplogroup TJ in a Finnish population. J Hum Genet 2001:46:64-9.

21 Carrieri G, Bonafe M, De Luca M, Rose G, Varcasia O, Bruni A, Maletta R, Nacmias B, Sorbi S, Corsonello F, Feraco E, Andreev KF, Yashin Al, Franceschi C, De Benedictis G. Mitochondrial DNA haplogroups and APOE4 allele are non-independent variables in sporadic Alzheimer's disease. Hum Genet 2001;108:194-8. 